\title{
ACCOUNTING ACTIVE LEARNING DAN HASIL PEMBELAJARANNYA: STUDI KASUS PADA UNIVERSITAS BERBASIS KEWIRAUSAHAAN
}

\author{
Maria Assumpta Evi Marlina \\ Universitas Ciputra \\ emarlina@ciputra.ac.id \\ Maichal Maichal \\ Universitas Ciputra \\ maichal@ciputra.ac.id
}

Received: $28-08-2017$

Revised: 02-10-2017

Accepted: $30-10-2017$

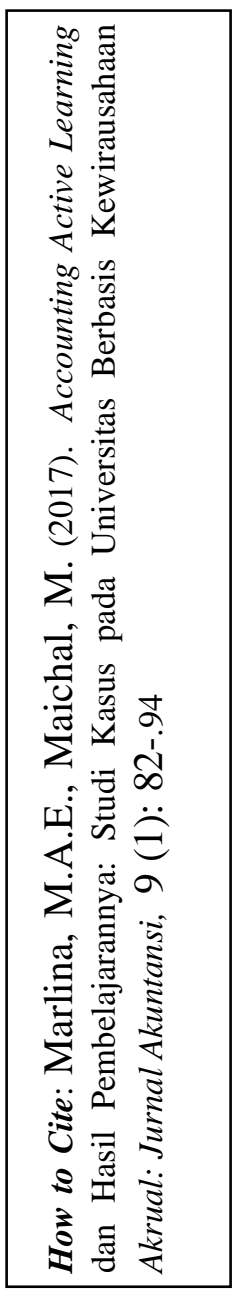

\section{ABSTRACT}

This research is conducted to enlarge the perception of Accounting Study Program students to their experience by using active learning method of learning (AAL) and learning outcomes. The AAL method is an accounting learning method that integrates accounting education with entrepreneurship education. The method used is by using triadik Rae model which is used as a tool in doing analysis. Informants in this research are seven students who have been through AAL learning process since semester one until semester seven. The result data is by conducting a forum group discussion, whose questions are directed to gain experience from informants during the AAL learning process and their application to learning outcomes that result in informants. The results of this study indicate the existence of AAL method, able to give a positive impact for students in terms of: establishing self-identity of entrepreneurship; a unique experience to be an entrepreneur in running a business project through a contextual learning process; and understanding towards. for the long term. The success of the AAL process is strongly felt by the integrase between students, parents, and institutions. The three elements must be united with the same goals and actions to achieve the success of learning.

Keywords: Accounting Active Learning, Entrepreneurship Learning, Entrepreneurial University,

\section{Abstrak}

Penelitian ini dilakukan untuk menggali persepsi mahasiswa Program Studi Akuntansi terhadap pengalamannya mengikuti proses pembelajaran dengan menggunakan metode accounting active learning (AAL) dan hasil pembelajarannya. Metode AAL merupakan metode pemnbelajaran akuntansi yang mengintegrasikan pendidikan akuntansi dengan pendidikan entrepreneurship. Metode penelitian yang digunakan adalah studi kasus dengan menggunakan triadic model Rae yang digunakan peneliti sebagai alat bantu dalam melakukan analisis. Informan dalam penelitian ini adalah tujuh mahasiswa yang telah melalui proses pembelajaran AAL sejak semester satu hingga semester tujuh. Data diperoleh dengan melakukan forum group discussion, yang pertanyaannya diarahkan untuk menggali pengalaman dari informan selama mengikuti proses pembelajaran AAL serta penerapannya terhadap hasil pembelajaran yang didapatkan informan. Hasil penelitian ini menunjukkan bahwa melalui metode AAL, mampu memberi dampak positif bagi mahasiswa dalam hal: pembentukan identitas diri yang entrepreneurial; mendapatkan pengalaman unik menjadi entrepreneur dalam menjalankan projek bisnis melalui proses pembelajaran kontekstual; dan pemahaman terhadap pentingnya kinerja entrepreneur untuk jangka panjang melalui proses negotiated entreprise. Keberhasilan proses AAL sangat dipengaruhi oleh integrase antara mahasiswa, orang tua, dan institusi. Tiga elemen tersebut harus secara bersamaan mempunyai tujuan dan tindakan yang sama untuk mencapai keberhasilan pembelajaran.

Kata kunci: Accounting Active Learning, Entrepreneurial Learning, Entrepreneurial University, integrasi pembelajaran akuntansi 
Marlina, Maichal, Accounting Active Learning dan Hasil Pembelajarannya...

\section{PENDAHULUAN}

Kemajuan suatu bangsa tidak lepas dari kualitas sumber daya manusianya, sedangkan kualitas sumber daya manusia dipengaruhi oleh kualitas pendidikannya (Badan Pusat Statistik , 2016). Keunggulan suatu bangsa dapat diraih dengan cepat melalui inovasi pendidikan yang dilakukan dengan cara mengintegrasikan pendidikan entrepreneurship kedalam kurikulum nasional sebagai core value (Ciputra, 2009: 55-59; Mayers dan Pruthi, 2011: 351). Pemerintah Indonesia saat ini juga telah menjalankan kegiatan Gerakan Kewirausahaan Nasional sejak tahun 2011 yang bertujuan untuk meningkatkan jumlah entrepreneur di Indonesia, dengan harapan dapat meningkatkan daya saing hingga tercapainya kesejahteraan bangsa Indonesia (Lubis, 2015: 235).

Pendidikan entrepreneurship merupakan program pendidikan yang memberikan pengetahuan, keahlian, dan motivasi kepada siswa agar mencapai kesuksesan dalam kegiatan entrepreneurship (Gerba, 2012: 227). Kegiatan entrepreneurship yang dimaksud merupakan sebuah proses yang saling berkaitan untuk menciptakan, mengenali dan bertindak terhadap peluang, dengan cara menggabungkan inovasi, penggambilan keputusan dan penguasaan suatu keahlian tertentu (Rae, 2007). Oleh karena itu, pendidikan entrepreneurship dapat dijalankan dengan efektif apabila dibentuk berdasarkan hubungan dialogis yang unik (saling terintegrasi) antar elemen yang relevan untuk menumbuhkan semangat entrepreneurial terhadap siswa (Jones dan Matlay, 2011; Othman et al., 2012; Storen, 2014). Menurut
Storen ada empat cara utama dalam memposisikan pendidikan entrepreneur-rship di pendidikan tinggi yaitu: pertama, sebagai sebuah pengalaman transformatif yang mampu menciptakan pola pikir entrepreneurial bagi seluruh pesertanya; kedua, sebagai sebuah jalur menuju start up bisnis dan atau keahlian khusus yang wajib dimiliki untuk merintis bisnis: ketiga, sebagai pemberi keterampilan dan pengetahuan kepada mahasiswa dalam ilmu pengetahuan dan seni bagi yang ingin mengkomersialkan kekayaan intelektual mereka; keempat, hanya sebagai matakualiah pilihan yang disediakan oleh institusi. Berdasarkan empat posisi pendidikan entrepreneurship tersebut yang paling berpengaruh terhadap pembentukan pola pikir entrepreneurial adalah pendidikan entrepreneurship yang dilakukan dalam jangka waktu lama dan berkelanjutan (Storen, 2014). Untuk itu, agar pola pikir entrepreneurial mahasiswa dapat terbentuk maka proses entrepreneurial learning perlu diterapkan dalam kehidupan sehari-hari mahasiswa selama menempuh pendidikan entrepreneurship.

Entrepreneurial learning merupakan sebuah proses pembelajaran yang dinamis atas kesadaran, refleksi, keterkaitan, dan penerapan yang melibatkan transformasi pengalaman dan pengetahuan kedalam sebuah hasil pembelajaran (learning outcome) yang fungsional (Rae, 2006: 42). Menurut Rae (2006: 42), konsep entrepreneurial learning terdiri dari: pertama, pengetahuan, perilaku dan pembelajaran afektif atau emosional; kedua, dipengaruhi oleh konteks di mana pembelajaran terjadi dan mencakup isi dari 
AKRUAL: Jurnal Akuntansi, volume 9, nomor 1, Oktober 2017, (82-94)

apayang dipelajari seperti proses di mana pembelajaran berlangsung; ketiga, merupakan aspek individual yaitu perbedaan-perbedaan personal dalam kemampuan untuk menghasilkan learning outcome yang berbeda antar masing-masing individu; keempat, terdapat hubungan yang erat antara proses entrepreneurial learning dengan pengenalan peluang, eksploitasi, kreativitas dan inovasi. Berdasarkan konsep tersebut, Rae (2005: 326; 2006: 43) merumuskan kerangka kerja konseptual untuk entrepreneurial learning, di mana kerangka kerja konseptual tersebut dibentuk berdasarkan tiga tema (triadic model) yaitu pembelajaran kontekstual (contextual learning), negotiated entreprise, pembentukan identitas pribadi dan sosial (personal \& social emergence).

Seuneke dan Bock (2015) menggunakan triadic model Rae (2005) dalam penelitiannya dan menemukan bahwa pembentukan identitas pribadi dan sosial dapat membantu perempuan dalam perusahaan pertanian keluarga untuk memperkenalkan aktivitas bisnis baru yang sekaligus menetapkan identitas baru dari perusahaan pertanian keluarganya. Selain itu, di dalam penelitian Seuneke dan Bock, melalui pembelajaran kontekstual, perempuan dalam pertanian keluarga berani keluar dari relasi yang telah dimiliki bisnis keluarganya, dan memulai mencari dan menemukan sebuah jeringan relasi yang baru dan belajar dari relasi tersebut. Terkait negotiated entreprise, Seuneke dan Bock menemukan bahwa melalui pengalaman dan jaringan relasi baru yang telah dibentuk, perempuan dalam pertanian keluarga mulai menegosiasikan orientasi pertanian di 84 masa depan menuju bentuk baru bisnis pertanian.

Dengan demikian, learning outcome seseorang untuk menjadi entrepreneur dapat diperoleh apabila terdapat interaksi yang saling mendukung dan saling berkaitan antara individu itu sendiri dan lingkungan sosialnya, pembelajaran yang kontekstual yang merupakan sebuah proses di mana seseorang menggunakan pengalaman mereka untuk mencari peluang, dan pengalaman pembelajaran dalam kegiatan nyata di perusahaan, selama berlangsungnya proses pembelajaran. Proses tersebut tidak akan berhasil membentuk entrepreneur apabila hanya dijalankan secara instan. Entrepreneurial learning merupakan proses yang terus-menerus dan berkelanjutan, sehingga seseorang yang belajar entrepreneurship mempunyai bekal yang lengkap berupa soft skill dan hard skill hingga siap menjadi entrepreneur. Hard skill dapat diperoleh melalui proses pembelajaran akademik, sedangkan soft skill dapat diperoleh selama proses pembelajaran menerapkan hard skill yang dimiliki dalam entrepreneurial learning.

Berbeda dengan hasil penelitian yang diperoleh Seuneke dan Bock, Mckeown (2010) menemukan bahwa triadic model yang dikembangkan oleh Rae tidak dapat memberikan penjelasan yang memadai dalam konteks tim manajemen pada Usaha Kecil Menengah (UKM), khususnya yang berkaitan dengan konsep negotiated enterprise. Menurut Mckeown, faktor penghambat berjalannya entrepreneurial learning di UKM adalah adanya hirarki kekuasaan dalam tim Copyright @ 2017 AKRUAL: Jurnal Akuntansi 
Marlina, Maichal, Accounting Active Learning dan Hasil Pembelajarannya...

manajemen UKM yang menentukan kesempatan untuk belajar dan yang cenderung menyebabkan timbulnya konflik yang menghambat iklim belajar. Triadic model yang dikembangkan oleh Rae, setidaknya dapat diaplikasikan pada dua bidang, yaitu bidang pendidikan dan praktisi bisnis (Rae, 2005: 332).

Universitas Ciputra (UC) merupakan universitas yang menerapkan entrepreneurial learning dalam proses pembelajarannya. Di Universitas Ciputra, entrepreneurship diajarkan sejak semester satu hingga semester tujuh dengan penekanan pada aspek creative selling, ideasi bisnis, pengembangan start-up bisnis, dan inovasi bisnis. Entrepreneurhip merupakan matakuliah yang wajib ditempuh oleh setiap mahasiswa UC apapun program studinya. Pada Program Studi Akuntansi (PSA), kurikulum PSA mengintegrasi-kan entrepreneurship dengan keilmuan akuntansi. Integrasi kurikulum tersebut didesain melalui program Accounting Active Learning (AAL). Melalui pendidikan AAL mahasiswa dibekali kemampuan untuk membaca peluang, menangkap peluang dengan mewujudkan start up bisnis hingga melakukan scale up dan scope up bisnisnya. Selama proses pembelajaran entrepreneurship berlangsung, mahasiswa menerapkan teori-teori yang disampaikan dalam matakuliah keilmuan akuntansi.

Metode pembelajaran AAL mensyaratkan mahasiswa untuk aktif selama mengikuti proses pembelajarannya, sehingga dapat menghasilkan hasil pembelajaran yang positif. Kemampuan mahasiswa menjadi lebih lengkap, tidak hanya kemampuan dalam keilmuan saja tetapi mempunyai juga kemampuan komunikasi, interpersonal, problem solving, berfikir analitis, dan berfikir kritis (McCarthy, 2016: 96; de Araujo dan Slomski, 2013: 26). Institusi yang menyelenggarakan pendidikan akuntansi perlu untuk memfasilitasi pengembangan soft skill akuntansi bagi mahasiswanya agar saat proses pembelajaran akuntansi, mahasiswa mampu mengembangkan hard skill dan soft skill nya secara bersamaan (Low et al., 2013: 31) sehingga gap antara pendidikan akuntansi dan prakteknya dapat dipersempit (Salem, 2013: 67). Institusi pendidikan mempunyai fungsi penting tidak hanya untuk membekali mahasiswa dengan keterampilan dan pengetahuan untuk menjadi akuntan profesional, tetapi juga memberikan bekal agar mahasiswa mampu mendalami peran akuntan dalam masyarakat dan perkembangan yang relevan dalam pemikiran akuntansi (Botes et al., 2014: 104). Tujuan dari penelitian ini adalah untuk menggali dampak metode pembelajaran AAL terhadap hasil pembelajaran berdasarkan persepsi mahasiswa.

\section{METODE}

Penelitian ini merupakan penelitian kualitatif menggunakan metode studi kasus. Penelitian studi kasus dapat memberikan bukti yang lebih efektif untuk menggambarkan peristiwa atau situasi yang kompleks dalam sebuah konteks tertentu, serta faktor-faktor dan proses yang terjadi pada tempat dan waktu tertentu di mana peristiwa tersebut berlangsung (Neuman, 2014; Basuki, 2016; Gumanti et al., 2016). Triadic model Rae digunakan peneliti sebagai alat untuk mempermudah memahami fenomena yang terjadi mengenai dampak pembelajaran 
menggunakan metode AAL berdasarkan persepsi informan dalam proses belajarnya.

Informasi pada penelitian ini diperoleh melalui wawancara mendalam dalam bentuk Focus Group Discussion (FGD), di mana pertanyaan diarahkan untuk mengali pengalaman informan dalam menjalani pembelajaran accounting active learning, serta implikasinya terhadap hasil pembelajaran yang diperoleh informan. Hasil wawancara tersebut kemudian dibuat transkrip dan diberikan kode berdasakan elemen-elemen yang ada dalam triadic model Rae yaitu pembentukan identitas, pembelajaran kontekstual, dan negotiated enterprise. Peneliti kemudian menganalisis dan mendeskripsikannya.

Informan penelitian ini terdiri dari tujuh orang mahasiswa PSA yang telah lulus (alumni) dan sedang menempuh tugas akhir. Kriteria informan tersebut diambil karena mereka telah melalui proses pembelajaran AAL sejak semester satu hingga semester tujuh. Adapun profil dari ketujuh informan disajikan dalam Tabel 1.

Tabel 1. Profil Informan Penelitian

\begin{tabular}{|c|c|c|c|c|}
\hline Informan & $\begin{array}{c}\text { Jenis } \\
\text { Kelamin }\end{array}$ & $\begin{array}{c}\text { Waktu } \\
\text { Pendidikan }\end{array}$ & $\begin{array}{l}\text { Project Bisnis } \\
\text { Terakhir }\end{array}$ & Deskripsi Project Bisnis \\
\hline Teofilus Pratama Putra & Pria & 7 semester & Holly Slime & $\begin{array}{l}\text { Produsen produk pembersih alat } \\
\text { elektronik }\end{array}$ \\
\hline Nurul Annisa Helda & Wanita & 8 semester & Arm Story & Produsen gelang berbahan batu alam \\
\hline Verliani Wijaya & Wanita & 8 semester & Dark Equal & Jasa penulisan naskah \\
\hline $\begin{array}{l}\text { Cinthya Felim } \\
\text { Gunawan }\end{array}$ & Wanita & 9 semester & Holly Pack & Distributor kemasan berbahan plastik \\
\hline Ryan Kevin Setiawan & Pria & 7 semester & Rellogio & Produsen jam dinding berbahan kayu \\
\hline Gavil & Pria & 7 semester & Possion Master & Distributor bubuk perasa minuman \\
\hline Jessica & Wanita & 7 semester & SAC & Distributor tas wanita \\
\hline
\end{tabular}

\section{HASIL DAN PEMBAHASAN}

Di sesi ini, peneliti memaparkan hasil temuan dari tujuh mahasiswa PSA-UC terkait dampak metode pembelajaran AAL terhadap hasil pembelajaran yang diperoleh mahasiswa baik dalam membentuk hardskill maupun softskill. Tujuh mahasiswa tersebut adalah Teo (TE), Nurul (NU), Verli (VE), Cinthya (CI), Ryan (RY), Gavil (GA), dan Jess (JE). TE, NU, VE, dan CI telah menyelesaikan tugas akhir, sedangkan RY, GA, dan JE sedang dalam proses menyelesaikan tugas akhir. Masingmasing mahasiswa tersebut mempunyai latar belakang keluarga yang berbeda-beda tentunya, tetapi oleh penulis digolongkan menjadi keluarga pengusaha dan bukan pengusaha.
Hanya TE yang mempunyai latar belakang bukan keluarga pengusaha. Sedangkan lainnya mempunyai latar belakang keluarga pengusaha.

Selama proses pembelajaran di PSA-UC, tujuh mahasiswa tersebut telah menjalankan projek bisnis masing-masing sejak semester dua. Selama mengalami proses pembelajaran, beberapa diantara mereka mengalami pergantian projek bisnis karena mengalami kegagalan. Masalah yang mereka hadapi sangat beragam, baik masalah yang timbul antar anggota kelompok, masalah dengan pemasok, masalah dengan produksi, dan masalah dengan pemasaran. Hasil penelitian ini menemukan bahwa hasil pembelajaran yang diperoleh informan melalui metode 
Marlina, Maichal, Accounting Active Learning dan Hasil Pembelajarannya...

pembelajaran AAL dibagi kedalam tiga kategori entrepreneurial learning yang dikemukakan oleh Rae (2005), yaitu pembentukan identitas, pengalaman pembelajaran kontekstual dan pengalaman professional melalui negotiated entreprise.

\section{Pembentukan Identitas}

Pembentukan identitas secara personal dan sosial merupakan pembangunan identitas entrepreneurial melalui pengalaman hidup dalam keluarga, pendidikan, pekerjaan, dan hubungan sosial. Membentuk identitas entrepreneurial berarti menjadi dan berperilaku sebagai entrepreneur (Rae, 2007: 45-50). Identitas informan sebagai entrepreneur terbentuk baik secara personal maupun sosial melalui proses yang mereka alami selama mengikuti proses entrepreneurial learning dengan menggunakan pendekatan AAL di PSA-UC. Berdasarakan hasil wawancara, secara jelas informan mengatakan bahwa mereka mengalami perubahan setelah mengikuti pembelajaran dengan AAL:

Tabel 2. Kutipan Wawancara Informan Terkait Identitas

\begin{tabular}{ll}
\hline TE: & "cara berpikir di kehidupan sehari- hari itu kan dipelajari juga di akutansi ... sangat dipakai dan \\
& sangat mempengaruhi pola pikir saya sekarang, secara pikiran kan juga lebih terbuka lebih \\
& berkembang jauh dibandingkan dulu..."
\end{tabular}

Adanya perubahan yang mereka rasakan khususnya terkait cara berpikir (pola pikir), pengendalian diri, pengenalan potensi diri, dan manajemen diri yang merupakan hasil dari proses pembelajaran sejak semester satu hingga semester tujuh. Mereka mampu merasakan perbedaan tersebut setelah mengalami pembelajaran dengan AAL. Selama mereka menjalankan projek bisnis, banyak hal yang membuat mereka akhirnya bisa merasakan perubahan tersebut. Perubahan tersebut semakin mempertajam identitas personal mereka. Berkaitan dengan identitas sosial, mahasiswa juga merasa lebih bisa bekerja dalam kelompok.

\section{Peran Keluarga dalam Pembentukan Identitas}

Berdasarkan hasil wawancara proses pembentukan identitas ternyata juga ditentukan oleh faktor keluarga. Keluarga juga berperan dalam pembentukan tersebut, seperti yang mereka katakan dalam wawancara:

Tabel 3. Kutipan Wawancara Informan Terkait Peran Keluarga terhadap Identitas

\begin{tabular}{|l|l|}
\hline TE: & $\begin{array}{l}\text { "kami itu sama- sama ditekan orang tua 'kamu lulus kami sebagai orang tua ngga nyanguin lagi' } \\
\text { orang tua ngga pernah membatasi saya ... jadi orang tua itu ngajari 'apa yang kamu ambil itu kamu } \\
\text { harus tanggung jawab'... jadi peran orang tua besar sekali dia ngasih tahu waktu saya down, orang } \\
\text { tua selalu ngasih saran saya harus seperti apa, ... karena semangat yang dikasih ke lingkungan saya } \\
\text { itu oleh orang tua saya" }\end{array}$ \\
\hline NU: & $\begin{array}{l}\text { "kalau kaya orang tua saya mau berinvestasi sesuatu, saya bisa bantu itu bu mikirin, ih kok } \\
\text { harganya terlalu mahal, kok kayaknya ini masa waktunya ngga lama, kok kayaknya perkerjaannya } \\
\text { ini lebih lama dan makan cost lebih banyak" }\end{array}$ \\
\hline
\end{tabular}


Dukungan keluarga ternyata berperan dalam proses pembentukan identitas sebagai entrepreneur. TE yang merasa tertekan karena orang tuanya tidak mau membiayai lagi hidupnya setelah lulus dari pendidikan S1, membuatnya merasa terpaksa harus bisa mencari sendiri sumber penghidupannya dengan menjalankan bisnis maupun sebagai pekerja paruh waktu. Demikian juga dengan NU. Orang tuanya mempunyai bisnis keluarga yang nantinya akan diserahkan kepada NU. Hal tersebut membuat NU merasa bertanggung jawab untuk ikut mengelola bisnis keluarganya. Melalui dukungan keluarga maka informaninforman tersebut akhirnya mempunyai kesempatan untuk mengikuti pendidikan menggunakan metode AAL hingga mereka mampu menyadari mendapatkan pengalaman dan merasakan perubahan positif sebagai mahasiswa PSA yang entrepreneurial.

\section{Pembelajaran Kontekstual}

Menurut Rae (2005: 328), pembelajaran kontekstual dapat terjadi dalam komunitas, industri, ataupun jaringan yang lain. Keterlibatan seseorang dalam lingkungan tersebut dapat membangun intuisi dan kemampuan seseorang untuk mengenali adanya peluang. Hal tersebut ditunjukkan dalam hasil wawancara kepada beberapa informan yang terdapat dalam Tabel 4. Melalui pembelajaran berbasis AAL, mahasiswa diwajibkan untuk membuat sebuah proyek bisnis. Keterlibatan mahasiswa pada proyek bisnis tersebut membuat mereka dapat merencanakan target kerja mereka, dan harus mencatat dan mendokumentasikan seluruh kegiatan proyek bisnis mereka. Selain proyek bisnis, mahasiswa juga diberikan kesempatan untuk kunjungan ke perusahaan ataupun instansi pemerintah untuk memperoleh informasi-informasi terkait pengembangan bisnis mereka, atau dapat melihat realita bagaimana perusahaan itu bekerja.

Tabel 4. Kutipan Wawancara Informan Terkait Pembelajaran Kontekstual

\begin{tabular}{|c|c|}
\hline TE: & $\begin{array}{l}\text { "jadi intinya akutansi dan entrepreneur itu apa yang kita lakukan harus bisa dipertanggung } \\
\text { jawabkan ... kami ukur setiap hari kami itu harus jual berapa dan kami itu udah punya kalender } \\
\text { sendiri itu, kalau tanggal merah kami harus jual berapa, harus kemana, nah itu ilmu akutansi yang } \\
\text { terukur kami harus melakukan itu harus bisa terstruktur, terukur harus diperhitungkan secara } \\
\text { matang- matang itu ya akhirnya kami impletasikan jadi target, kami bikin timeline sendiri ... kami } \\
\text { bikin papan sendiri dengan nentuin prioritas kami yang utama itu apa kalau kami punya ide bisnis } \\
\text {... target yang real bisnis kaya kami itu dalam tiga bulan kedepan pingin apa, kami pingin bisnis } \\
\text { yang seperti apa nah itu yang kami lakukan sampai saat ini seperti itu" }\end{array}$ \\
\hline NU: & $\begin{array}{l}\text { "kampus juga kasih opportunity ke kita untuk ikut kunjungan ... kaya kejadian kemarin saya } \\
\text { kunjungan dikantor pajak, pulang saya cerita sama orang tua ... jadi kita lebih update lagi bu ... } \\
\text { pada waktu masih awal kita buat projek pasti kita mengenal satu sama lain dulu toh bu ... tapi } \\
\text { ternyata bisnis itu ngga hanya tentang teman, bisnis- itu ya bisnis, teman ya teman" }\end{array}$ \\
\hline VE: & $\begin{array}{l}\text { "disuruh buat plan bisnis dan langsung praktek ke Taman Bungkul, ya jadi bener- bener } \\
\text { pengalamannya nol tapi disuruh belajar buat sesuatu yang sama sekali ngga penah dibuat" }\end{array}$ \\
\hline JE: & $\begin{array}{l}\text { "kalau kalau yang udah aku jalani berdasarkan pengalaman kalau kita ikut praktek itu jadi ngerti } \\
\text { gitu loh ... sudah melakukan praktek disini kita tahu bisnis ini butuh nya gimana- gimana jadi kita } \\
\text { kayak udah punya pengalaman" }\end{array}$ \\
\hline RY: & $\begin{array}{l}\text { "ada praktek di lapangannya jadi kita bisa pintar mengotak-atik teorinya kira-kira bener pada waktu } \\
\text { kondisi di lapangan seperti apa, apalagi kondisi bisnis yang sering berubah-ubah" }\end{array}$ \\
\hline
\end{tabular}


Marlina, Maichal, Accounting Active Learning dan Hasil Pembelajarannya...

Pembelajaran kontekstual yang disajikan melalui praktek bisnis, kunjungan, dan proyek bisnis menghadirkan pengalaman nyata bagi mahasiswa dalam melaksanakan sebuah bisnis. Melalui kegiatan tersebut mahasiswa menjadi paham teori dan dapat melihat mana teori yang berlaku untuk sebuah kondisi bisnis mereka dan mana teori yang tidak relevan dengan kondisi bisnis mereka. Selain itu, melalui proyek bisnis, mahasiswa juga dapat memahami bahwa bisnis itu sangat komplek. Menjalankan bisnis membutuh-kan kecermatan, manajemen waktu yang sangat baik dan kepekaan terhadap perubahanperubahan perilaku konsumen dan kebijakan pemerintah. Berdasarkan pengalaman dari masing-masing informan tersebut, tampak bahwa proses pembelajaran AAL yang diterapkan sejak semester satu hingga semester tujuh (yang tentunya bukan merupakan proses pembelajaran yang singkat) dapat membangun intuisi dan kemampuan mahasiswa dalam mengidentifikasi adanya peluang, hingga memampukan mereka untuk menangkap peluang untuk diterapkan dalam projek bisnisnya.

Melalui proses tersebut, secara bersamaan kemampuan hard skill dan soft skill mereka semakin berkembang. Mereka mampu menerapkan keilmuan akuntansi yang mereka dapatkan dikelas kedalam projek bisnis yang mereka jalankan. Sebagai contoh, mereka menggunakan teori yang diajarkan dikelas untuk mengidentifikasi peluang. Apabila peluang tersebut dapat dijalankan, maka mereka akan ambil peluang tersebut. Oleh karena itu, contextual learning memiliki peran penting dalam pembentukan pola pikir entrepreneurship pada informan.

Tabel 5. Kutipan Wawancara Hasil Pembelajaran Kontekstual

\footnotetext{
TE: "membantu UKM di Mojokerto itu juga sebetulnya ehmm apa ya pengalamannya banyak banget ... belajar di kampus secara akademis dan kami juga belajar bisnis yang langsung dan real untuk level UKM ... jadi liat peluang sebenerya kan gak tiba- tiba muncul aja, ada proses ... pelajarannya diajarkan dari semester satu sampai semester tujuh sampai saya lulus kan diajarkan, jadi kemampuan untuk berbisnis nya semakin tajam ... jadi kalau sekarang bicara kembali ke peluang ya kuncinya punya networking jadi punya pengalaman ... ketika relasi semakin luas jadi otomatis informasi yang saya dapatkan semakin banyak, nah semakin banyak informasi itu mempengaruhi peluang kita, dan cara melihat peluang kita semakin besar"

NU: hitung HPP sih bu hehe jadi setiap minggu kita juga harus ada presentasi pencapaian kita, trus dikasih masukan sama temen- temen, dosen, dan lain- lain jadi kita kayak lebih belajar gitu loh bu ... jadi kita punya patokan target dan waktu kapan kita harus menjual berapa kaya gitu ... bisa lihat peluang ngga hanya setelah lulus kayaknya semenjak kuliah entrepreneurship ... jadi saya lebih dilatih, kuliah disini itu lebih terangsang untuk bisa di luar itu lebih reasonable lagi bisa lebih berpikir lagi sebelum mengambil tindakan"

CI: "real projek bisnis dan cara pembuatan akutansinya kan juga bisa lebih dimengerti sih karena kita menjalani itu sendiri ... kulak sama orang gapapa sih tapi harus ada inovasi apa, cara jual kaya gimana supaya beda sama orang lain ... bisnis makanan ini bisa untung berapa trus habis itu inovasi nya bisa diterima masyarakat atau ngga ... jadi mikir bisnis itu ke arah mending cari bisnis yang gak ada expired nya atau lebih bisa ke jangka panjang gitu"

GA: "misal kalau ada barang baru, inovasi baru ini bisa dibisniskan, cuma bisa kejual ngga kaya gitu sih, cara pikirnya berubah kaya gitu sih, jadi bisa menangkap peluang lebih cepet"

JE: "ehm kalau saya pribadi saya sekarang kalau misalkan ehm saya dapet peluang saya lebih perhitungkan sih"

RY: $\quad$ "jadi orientasi saya kadang- kadang kalu ngelihat barang ini kalau dijual cuan nya berapa ya ... saya kalau ngelihat barang- barang atau bicara sama orang mikir cost nya berapa sih coba cari- cari disana, trus kalau misalnya diterapin ke bisnis saya sendiri di sekarang dan kedepannya nanti kan jadinya lebih bagus bu"
} 


VE: "kita lihat ada peluang untuk cuan sedikit itu pasti langsung diambil ... misalnya saya butuh print
tengah malam misalnya besok kumpul 'aduh ngga ada print buka' sebenernya ini bisa sih jadi
peluang untuk ini, saya kepikiran waktu itu apa itu aku ajukan ke gojek jadinya saya buka goprint
disana saya cuma tinggal pinjam beberapa orang gojek trus tinggal open 24 hours ... begitu ada
orang yang bilang sekaligus deh aku yang bayar ongkir nya, oh kita bisa ambil peluang dari biaya
ongkinnya kita naikan harga berapa kaya gitu"

Tabel 5 memberikan informasi kutipan wawancara yang merupakan hasil pembelajaran kontekstual yang diperoleh mahasiswa. Mahasiswa akuntansi yang dibekali dengan berbagai teori-teori akuntansi dapat mempraktekan secara langsung teori tersebut. salah satu konsep yang sering digunakan informan adalah metode perhitungan harga pokok. Selain itu, informan juga menyadari bahwa memiliki relasi merupakan salah satu kunci untuk dapat meraih kesuksesan bisnis. Melalui relasi, informan dapat memiliki informasi-informasi yang dalam informasi tersebut banyak peluang-peluang yang dapat dikerjakan dan melalui relasi dapat memuat informan semakin peka melihat peluang. Informan juga melihat bahwa inovasi yang tepat adalah inovasi yang dapat diterima oleh masyarakat. informan juga menjadi semakin peka dengan kebutuhan yang dapat dijadikan bisnis. Salah satu contohnya disampaikan dalam kutipan wawancara adalah terkait kebutuhan untuk mencetak dokumen di malam hari.

\section{Negotiated Enterprise}

Konsep negotiated entrepreise adalah kondisi dimana sebuah perusahaan tidak hanya dimainkan oleh satu orang saja, tetapi dijalankan karena adanya negosiasi dengan pihak-pihak yang berkaitan seperti konsumen, pemasok, karyawan, atau mitra berbisnis (Rae, 2005: 329). Para informan juga menyampaikan bahwa pada saat mereka menjalankan bisnis, mereka berinteraksi dengan pihak-pihak yang berkaitan. Hal tersebut tampak dalam hasil wawancara sebagai berikut:

Tabel 6. Kutipan Wawancara Terkait Negotiated Entreprise

\footnotetext{
TE: "semester satu itu belajar jadi sales, waktu itu UC berkerja sama dengan berbagai vendor, saya waktu itu memilih Philips, pertama kali itu saya belajar bicara dengan orang lain, belajar nawarin produk ... entrepreneurship itu bukan hanya untung dan rugi tapi bagaimana kita bisa bangun kehidupan sendiri dan kehidupan orang lain misalnya kita punya bisnis punya karyawan bagaimana kita memperhatikan orang ... setiap anggota wajib menyumbangkan ide, itu yang sampai sekarang saya terapkan sama Chris yang Holy Slime itu"

NU: "kita harus bangun bisnis ada tanggung jawab jadi CFO jadi CEO harus bangun pagi ... kan kalau di accounting ini dia partner toh bu dan tim jadi saya bisa lebih mengendalikan diri saya dan lebih bisa teamwork gitu loh bu kalau berkerja, jadi saya mikir kalau misalnya sama- sama mau kemauan nya masing- masing bisnis nya ngga akan jalan, target nya nggga akan tercapai kalau misalnya si A mau begini si B mau begini"

CI: "disaat saya punya karyawan kan misal kaya sistem punish atau reward itu kadang saya pakai ke karyawan"

RY: "SPM juga itu kita pakai waktu kita buka stand itu bagaimana supaya nge push karyawan supaya jualan banyak gitu ... selama menjalani proyek bisnis, misal bagaimana ngadepin masalah pas lagi ribut kelompok ... nah itu gimana kita muter otak biar bisa selesai ... perpecahan antar teman ya itu terjadi sih karena kita bisnis waktu awal- awal kita ngga tahu sama sekali sih A ini seperti apa si B seperti apa ... mungkin ada kebedaan pola pikir atau cara kerja yang tidak cocok dan itu efeknya panjang dan pecah"

VE: $\quad$ "sekarang saya menjalankan projek dengan sebuah perusahaan yang cari saya duluan ... yang jadi internal problem yang sebenernya kecil jadi besar
} 
GA: "waktu kita cari- cari sponsor itu bener- bener bagaimana cara kita ngomong sama orang yang lebih besar ... kita harus ngerti bahaya atau ngga orang yang nawarin kita produk, kita harus lebih selektif lagi"

Pada saat seseorang menjalankan bisnis, ternyata tidak bisa dijalankan sendirian. Bisnis tersebut harus terkoneksi dan bernegosiasi dengan pihak-pihak yang berkaitan. Seperti yang sudah disampaikan para informan, bahwa dalam menjalankan bisnisnya, mereka mempunyai banyak pengalaman yang berhubungan dengan karyawan, mitra bisnis, dan pihak luar. Entrepreneur tentunya harus mampu memecahkan konflik-konflik yang terjadi agar bisnisnya tetap jalan. Melalui pengalaman tersebut kematangan seorang entrepreneur semakin teruji. Pengalaman negotiated entreprise dialami informan sejak mereka semester satu. Pada semester satu, mahasiswa diminta untuk menjual produkproduk mitra dan melalui kegiatan tersebut, mahasiswa belajar untuk berkomunikasi tentang cara menjual yang tepat bahkan melalukan negosiasi dengan konsumen.

Pada semester selanjutnya, mahasiswa diminta untuk membuat proyek bisnis secara berkelompok. Melalui kelompok bisnis tersebut, mahasiswa membagi peran masingmasing dalam proyek bisnis yang dijalankan. Mahasiswa dapat belajar mengenai pengendalian diri dan kerja tim yang benar. Mahasiswa juga belajar bagaimana menetapkan kesatuan tujuan dalam perusahaan demi tercapainya tujuan bersama. Konflik juga merupakan hal yang sangat umum dialami dalam sebuah proyek bisnis. Melalui proyek bisnis yang dijalankan, mereka sejak dini telah mengalami bagaimana konflik tersebut dan pada akhirnya mahasiswa belajar mengenai bagaimana cara penyelesaian konflik.

\section{PEMBAHASAN}

Salah satu tantangan yang dapat dihadapi oleh calon pendiri perusahaan adalah terkait mengintegrasikan identitas pendiri ke dalam keseluruhan konsep diri yang mungkin terdiri dari identitas yang saling bertentangan atau saling bersaing (Hoang \& Gimeno, 2010). Identitas diri pendiri menjadi penting karena identitas pendiri akan menjadi arah bagi identitas perusahaan (Leitch \& Harrison, 2016). Menurut Hoang dan Gimeno (2010), identitas peran pendiri yang berbeda dapat mempengaruhi tingkat dan jenis ketekunan yang ditunjukkan oleh pendirinya di bawah kondisi umpan balik negatif yang dapat terjadi kerena dinamika bisnis. Melalui pendidikan AAL yang diterapkan di Program Studi Akuntansi Universitas Ciputra, identitas diri informan terbentuk pada aspek pola pikir entrepreneurial informan. Pola pikir yang terbentuk adalah informan menjadi lebih peka melihat peluang dan memiliki kemampuan untuk menajemen diri dan kerja tim. Selain pendidikan berbasis ALL, penelitian ini juga menemukan bahwa orangtua juga memiliki peran dalam membentuk identitas entrepreneurial informan.

Peran orangtua dapat berasal dari jenis pola didikan yang diterapkan orangtua untuk mendidik anaknya (Tam et al., 2012; Lin \& Billingham, 2014). Disiplin dan tuntutan yang diberikan orangtua dapat mendorong 
AKRUAL: Jurnal Akuntansi, volume 9, nomor 1, Oktober 2017, (82-94)

mahasiswa untuk lebih serius dalam menjalankan proyek bisnisnya. Selain itu, dukungan orangtua yang dapat berupa kesempatan yang diberikan kepada anak untuk memberikan masukan terhadap bisnis orangtua dapat memberikan aktualisasi diri bagi anak terhadap bisnis orangtuanya. Pembelajaran kontekstual juga memberikan hasil pembelajaran yang berguna bagi informan, khususnya terkait pengalaman berwirausaha. Berdasarkan kutipan wawancara yang terdapat pada Tabel 4, pembelajaran kontekstual yang dialami mahasiswa adalah membuat proposal rencana bisnis dan mengeksekusi rencana tersebut, serta kunjungan ke industri maupun ke instansi pemerintah. Melalui eksekusi proyek bisnis, mahasiswa dapat mempelajari mengenai administrasi perusahaan dan dokumentasi perusahaan. Serta melalui pengalaman berbisnis, mahasiswa jadi paham mengenai teori yang berlaku dan teori yang tidak relevan bagi bisnisnya.

Pengetahuan spesifik dan kemampuan kognitif pengusaha pada setiap tahap proses pembelajaran, merupakan faktor yang pada akhirnya menentukan seberapa banyak pengusaha dapat belajar dari kesalahan kinerja yang diberikan (Petkova, 2009). Pada saat mengerjakan proyek bisnis, mahasiswa sering kali hadapkan dengan berbagai masalah, mulai dari masalah internal pada kelompoknya, maupun masalah eksternal terkait pemasok maupun konsumen. Masalah internal yang sering dihadapi adalah ketidakcocokan pemikiran antara anggota kelompok yang pada akhirnya membuat kelompok tersebut bubar. Melalui negotiated entreprise, mahasiswa dapat belajar dari setiap kegagalan yang 92 dialami dalam bisnisnya. Mahasiswa jadi paham bahwa ternyata kesatuan visi dan misi antar anggota merupakan aspek yang penting demi terciptanya kinerja jangka panjang yang baik dari proyek bisnis yang mereka kerjakan. Pembelajaran entrepreneurial learning yang diwujudkan dengan pembelajaran berbasis AAL memberikan kesempatan bagi mahasiswa untuk belajar teori sekaligus melihat dan mengaplikasikan teori tersebut di proyek bisnisnya. Selain itu, pembelajaran AAL juga mengasah afeksi mahasiswa dalam berbagai persoalan bisnis yang mereka hadapi.

\section{KESIMPULAN}

Berdasarkan persepsi mahasiswa PSA, pendidikan akuntansi dengan menggunakan metode AAL mampu memberikan dampak positif dalam hal: pembentukan identitas diri yang entrepreneurial; mendapatkan pengalaman unik menjadi entrepreneur dalam menjalankan projek bisnis melalui proses pembelajaran kontekstual; dan pemahaman terhadap pentingnya kinerja entrepreneur untuk jangka panjang melalui proses negotiated entreprise. Melalui metode AAL, mahasiswa tidak hanya mendapatkan pengetahuan/teori dari dosen/mentor, tetapi mahasiswa juga menerapkan pengetahuan/teori tersebut kedalam projek bisnis yang dijalankan. Oleh karena itu, metode pembelajaran AAL memungkinkan mahasiswa tidak hanya tahu dan paham pengetahuan/teori, tetapi mampu menerapkan dan mengalami sendiri dampaknya dalam menjalankan projek bisnis.

Melalui triadic model RAE, peneliti menemukan bahwa antara mahasiswa, orang tua, dan institusi harus bersinergi agar tujuan 
Marlina, Maichal, Accounting Active Learning dan Hasil Pembelajarannya...

pembelaran dapat tercapai. Proses pembelajaran tidak akan berhasil dengan baik apabila salah satu elemen tersebut tidak mendukung. Metode AAL mampu mebuat mahasiswa menjadi lebih percaya diri untuk memasuki dunia kerja karena merasa mempunyai bekal soft skill dan hard skill. Harapan peneliti dalam dunia pendidikan saat ini dan untuk masa yang akan datang adalah segera timbul metode-metode pembelajaran yang baru dalam semua bidang pendidikan untuk menjembatani adanya jeda/jarak antara soft skill dan hard skill bagi mahasiswa, sehingga mereka menjadi lebih siap terjun dalam dunia kerja.

\section{SARAN}

Penelitian dengan menggunakan triadic model Rae telah dilakukan pada para entrepreneur (Rae, 2005, 2006; Seuneke dan Bock, 2015) dan pada mahasiswa yang mendapatkan pembelajaran dengan menggunakan metode AAL di pendidikan tinggi yang berbasis entrepreneurship. Penelitian selanjutnya dapat dilakukan pada siswa yang institusinya berbasis entrepreneurship, baik pada tingkat dasar, menengah, maupun atas.

\section{UCAPAN TERIMA KASIH}

Ucapan terima kasih peneliti sampaikan kepada Kementrian Riset, Teknologi dan Pendidikan Tinggi Republik Indonesia atas hibah yang telah diberikan kepada peneliti, hingga peneliti mampu menyelesaikan penelitian ini dan peneliti mendapat tambahan wawasan dan pengalaman dalam melakukan penelitian ilmiah.

\section{REFERENSI}

Badan, P. S. (2016). Potret Pendidikan Indonesia: Statistik Pendidikan 2016. Jakarta: Badan Pusat Statistik.

Basuki. (2016). Metode Penelitian Akuntansi dan Manajemen Berbasis Studi Kasus. Surabaya: Airlangga University Press.

Botes, V., Low, M., \& Chapman, J. (2014). Is Accounting Education Sufficiently Sustainable? Sustainability Accounting, Management and Policy Journal, 5(1), 95-124. doi:10.1108/sampj-11-2012-0041

Ciputra. (2009). Quantum Leap: Entrepreneurship Mengubah Masa Depan Bangsa dan Masa Depan Anda. Jakarta: Elex Media Komputindo.

de Araujo, A. M., \& Slomski, V. G. (2013). Active Learning Methods-An Analysis of Applications and Experiences in Brazilian Accounting Teaching. Creative Education, 4(12B), 20-27. doi:10.4236/ce.2013.412a2004

Gerba, D. T. (2012). The Context of Entrepreneurship Education in Ethiopian Universities. Management Research Review, 35(3/4), 225-244. doi:10.1108/01409171211210136

Gumanti, T. A., Yunidar, \& Syahruddin. (2016). Metode Penelitian Pendidikan. Jakarta: Mitra Wacana Media.

Hoang, H., \& Gimeno, J. (2010). Founding, Becoming a Founder: How Founder Role Identity Affects Entrepreneurial Transitions and Persistence in. Journal of Business Venturing, 25, 41-53. doi:10.1016/j.jbusvent.2008.07.002Jon es, C., \& Matlay, H. (2011). Understanding the Heterogeneity of Entrepreneurship Education: Going Beyond Gartner. Education + Training, 53(8/9), 692-703. doi:10.1108/00400911111185026

Leitch, C. M., \& Harrison, R. T. (2016). Identity, identity formation and identity work in entrepreneurship: conceptual developments and empirical applications. Entrepreneurship \& Regional Development, 28(3-4), 177-190. doi:10.1080/08985626.2016.1155740 
AKRUAL: Jurnal Akuntansi, volume 9, nomor 1, Oktober 2017, (82-94)

Lin, Y.-C., \& Billingham, R. E. (2014). Relationship Between Parenting Styles and Gender Role Identity in College Students. Psychological Reports: Relationships \& Communications, 114(1), 1-22. doi:10.2466/21.09.pr0.114k13w4

Low, M., Samkin, G., \& Liu, C. (2013). Accounting Education and the Provision of Soft Skills: Implications of the recent NZICA CA Academic requirement changes. e-Journal of Business Education \& Scholarship of Teaching, 7(1), 1-33.

Lubis, R. L. (2015). The "Triple-I" Learning Model of Entrepreneurship Education in Indonesia: Where do we go from here? International Journal of Arts \& Sciences, 8(7), 233-264.

McCarthy, M. (2016). Experiential Learning Theory: From Theory to Practice. Journal of Business \& Economic Research, 14(3), 91-100. doi:10.19030/jber.v14i3.9749

Mckeown, I. (2010). No More Heroes: Entrepreneurial Learning in the SME Management Team. Industry \& Higher Education, 24(6), 429-441. doi:10.5367/ihe.2010.0012

Meyers, A. D., \& Pruthi, S. (2011). Academic Entrepreneurship, Entrepreneurial Universities and Biotechnology. Journal of Commercial Biotechnology, 17, 349-357. doi:10.1057/jcb.2011.22

Neuma, W. L. (2014). Social Research Methods: Qualitative and Quantitative Approaches (7th ed). Harlow: Pearson Education Limited.

Othman, N., Hashim, N., \& Wahid, H. A. (2012). Readiness Towards Entreprenuership Education - Students and Malaysian Universities. Education + Training, 54(8/9), 697-708. doi:10.1108/00400911211274837
Petkova, A. P. (2009). A theory of entrepreneurial learning from performance errors. International Entrepreneurship and Management Journal, 5, 345. doi:10.1007/s11365-008-0075-2

Rae, D. (2005). Entrepreneurial Learning: a Narrative-Based Conceptual Model. Journal of Small Business and Entreprise Development, 12(3), 323335. doi:10.1108/14626000510612259

Rae, D. (2006). Entrepreneurial Learning: a Conceptual Framework for Technology-Based Entreprise. Technology Analysis \& Strategic Management, 8(1), 39-56. doi:10.1080/09537320500520494

Rae, D. (2007). Entrepreneurship from Opportunity to Action. New York: Palgrave Macmillan.

Salem, M. S. (2013). The Future of Accounting as a Subject in a Business School: a Literature Review. The Journal of Human Resource and Adult Learning, 9(2), 61-69.

Seuneke, P., \& Bock, B. B. (2015). Exploring the Roles of Women in the Development of Multifunctional Entrepreneurship on Family Farms: an Entrepreneurial Learning Approach. NJAS - Wageningen Journal of Life Sciences, 74-75, 41-50. doi:10.1016/j.njas.2015.07.001

Storen, L. A. (2014). Entrepreneurship in Higher Education, Impacts on Graduates' Intrepreneurial Intentions, Activity, and Learning Outcome. Education + Training, 56(8/9), 795813. doi:10.1108/et-06-2014-0070

Tam, C.-L., Chong, A., Kadirvelu, A., \& Khoo, Y.-T. (2012). Parenting Styles and Self-Efficacy of Adolescents: Malaysian Scenario. Global Journal of Human Social Science Arts \& Humanities, 12(14). 